\title{
FICCIÓN, FORMACIÓN DE SUBJETIVIDADES
} POLÍTICAS Y NARRACIONES (AUTO) BIOGRÁFICAS. LA CIRCULACIÓN DE RELATOS COMO CAMINO HACIA

LAALTERIDAD'

FICTION, FORMATION OF POLITICAL

SUBJECTIVITIES AND (AUTO) BIOGRAPHICAL

NARRATIVES. CIRCULATION OF STORIES AS A

PATHWAY TOWARDS ALTERITY

\section{Edisson Leonardo Parra Herrera**}

Universidad De Los Andes

"Detrás de la narratividad hay (...) una vuelta a lo dionisiaco frente al logos"

Paredes (2011)

\section{RESUMEN}

Este artículo reflexiona sobre la posibilidad de formar subjetividades políticas a partir de

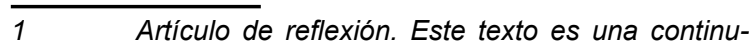
ación de algunas ideas planteadas en la tesis doctoral: Voluntad de ficción, subjetividades políticas y narrativas (auto) biográficas. Una experiencia de formación política con estudiantes de secundaria (Parra, 2020). Durante el proceso de investigación el autor recibió apoyo financiero de la Secretaria de Educación Distrital dentro del programa Apoyo a Posgrados. De igual manera, fue beneficiario de la convocatoria 757 de COLCIENCIAS para doctorados nacionales.

** Doctor en Educación de la Universidad de los Andes. Magíster en Filosofía de la Pontifica Universidad Javeriana. Licenciado en Educación Básica con Énfasis en Ciencias Sociales de la Universidad Pedagógica Nacional. Actualmente es Directivo Docente Coordinador del Colegio San Agustín IED. Bogotá, Colombia. Correo electrónico: el.parra10@uniandes.edu.co. Orcid: https://orcid.org/0000-0001-8708-1875

narraciones (auto) biográficas. Para ello centra su atención en la ficción como herramienta que permite la transfiguración de la propia subjetividad y el acercamiento con la alteridad. En un primer momento, con Paul Ricoeur, se trabaja la relación entre vida y narración. Así, se resalta la condición prenarrativa de la existencia y se afirma que la vida se narra y la narración se vive. En el mismo camino, en un segundo momento, se establece la relación entre la configuración de la trama y el nacimiento de la subjetividad para definir esta última como identidad narrativa. En tercera medida, se atiende al potencial de la construcción de relatos (auto) biográficos para 
conocerse y transfigurarse. Esto, en tanto la razón narrativa es entendida como una forma de inteligibilidad del mundo. En el cuarto punto, se caracteriza el sentido político de la narración y a partir del elemento ficcional presente en ella se afirma que es una herramienta de formación de la subjetividad política; los relatos (auto) biográficos cuando circulan ofrecen, aunque no por sí mismos, las condiciones para que se dé el encuentro con la otredad.

\section{PALABRAS CLAVE:}

narración (auto) biográfica, ficción, subjetividades políticas, razón narrativa, identidad narrativa, alteridad.

\section{ABSTRACT:}

this article reflects upon the possibility to make political subjectivities from (auto) biographical narratives. For that purpose, it focuses its attention on fiction as a tool that allows the transfiguration of subjectivity itself and the approach to alterity. Initially, with Paul Ricoeur, the relationship between life and narrative is worked on. Therefore, the pre-narrative condition of the existence is highlighted and it is stated that the life is narrated and that the narrative is lived. Secondly, it is also addressed the relationship between the configuration of the plot and the birth of the subjectivity to define the latter as narrative identity. Thirdly, the potential of the construction of (auto) biographical narratives to get to know and transfigure oneself is addressed. This, as a narrative reason, is understood as a form of intelligibility of the world. In the fourth point, the political meaning of the narrative is characterized and based on the fictional element present in it, it is stated that it is a tool for the formation of political subjectivity; when the (auto) biographical accounts circulate, they offer, although not by themselves, the conditions for an encounter with alterity.

\section{KEYWORDS:}

(auto) biographical narratives, fiction, political subjectivities, narrative reason, narrative identity, alterity.

\section{INTRODUCCIÓN: LAS NARRACIONES (AUTO) BIOGRÁFICAS COMO CONFIGURADORAS -DEL SENTIDO- DE LA EXPERIENCIA COMPARTIDA}

En su temprano ensayo Sobre verdad y mentira en sentido extramoral Nietzsche caracteriza al hombre como un sujeto 'artísticamente creador'. En consecuencia, no son relaciones de causalidad las que regulan el encuentro entre el sujeto y el objeto, sino que es mediado por una 'conducta estética'. Así, traducimos nuestra interacción con las cosas a un lenguaje fantasmagórico y para ello se necesita "una esfera intermedia y una fuerza mediadora, libres ambas para poetizar e inventar" (Nietzsche, 2006, p. 30); dicha fuerza denominada fantasía ha configurado nuestro mundo. De ahí que el universo que conocemos no sea más que el resultado de la sedimentación de las metáforas usadas para referirnos a él, pero hemos olvidado su carácter metafórico; este impulso fundamental del hombre hacia la construcción de metáforas continúa desplegándose en las diferentes esferas humanas.

De este modo, hemos edificado nuestro mundo por medio de ficciones narrativas que ahora damos por sentadas. Tanto en la vida abstracta como en la cotidiana utilizamos relatos sustentados en una óptica de la vida. Todos los días contamos historias de lo que nos pasa, de lo que vemos y de lo que sabemos. Desde esta presencia universal del relato es posible postular que el hombre es un ser narrador por naturaleza; sin embargo, esta naturalidad puede ser cuestionada al decir que la vida se vive y la historia se narra. Ahora bien, como señala Ricoeur (2006), si bien es cierto que existe un abismo insalvable entre vida y ficción (narración) 
es gracias a la posibilidad que tenemos de realizar una 'comprensión narrativa' de nuestra vida que superamos sus diferencias. Así, la vida es narrada y las narraciones son vividas.

Por tanto, es posible afirmar que el acto narrativo tiene su fuente en la experiencia. A pesar de ello, asistimos a una declinación de la narración que se basa en la experiencia ya sea nuestra o de otros. Esto es producido y trae como consecuencia el abandono de la capacidad comunicativa y de las relaciones con los otros (Benjamín, 1998; Larrosa, 2003). Para hacerle frente, es necesario buscar de nuevo la forma de comunicación que tiene su asidero en la experiencia del mundo y encontrarnos para construir vínculos nuevamente con los otros. En este trasegar, que no es una vuelta a un origen deseado, quiero preguntarme ¿cuál es el papel de la narración en la formación subjetiva? Para abordar esta cuestión, con miras al rescate de la experiencia, considero adecuado penetrar en la esfera de la narración (auto) biográfica. Dado que, en este campo se propugna por darle a la experiencia propia y compartida un estatuto ontológico y epistemológico.

En especial, dirijo la mirada a la ficción como elemento narrativo y forma de narración que se nutre de la experiencia. Hay que aclarar que los relatos se entienden como ficcionales, por un lado, en tanto al contar su historia los sujetos realizan una edición de sus experiencias. Por otro, la ficción puede ser entendida como la posibilidad que tienen los sujetos de imaginar e inventar acontecimientos que no son necesariamente reales, pero que configuran realidad. Es decir, por medio de la ficcionalidad del relato es posible reconstruir el pasado y verse o proyectarse en hechos imaginados, pero que transfiguran la subjetividad. Esta transfiguración es factible dado que no solamente los relatos se sustentan en la experiencia, sino que también la producen.

Ahora bien, no puede pensarse que existe una experiencia puramente individual, pues toda experiencia se da a partir de relaciones. Dado que existe una ontología relacional que se hace evidente en el entramado narrativo. De este modo, recuperar las formas narrativas sustentadas en la experiencia implica reconstruir los vínculos con la alteridad. En todo caso, para que en las narraciones no solo aparezca la vida propia, sino que efectivamente la experiencia ajena que escuchamos haga parte de nosotros, es necesaria: "una dialéctica de escucha recíproca y de estar siempre abierto a lo otro, que conlleva la exigencia de estar dispuesto a la afectación desde el afuera y a la consiguiente reflexividad sobre sí mismos" (Murillo, 2016).

La narración, entendida como una forma de inteligibilidad, implica un pensamiento alejado de los puros razonamientos lógicos. Pues, "si los individuos acceden a su vida narrativamente, entonces, la comprensión de la condición humana se debe estudiar de manera narrativa" (Clandinin y Conelly, Citado por García, 2015, p. 196). En este sentido, Ricoeur recurre a Sócrates para señalar que una vida que no es 'examinada' no merece vivirse y muestra con Aristóteles la existencia de una 'inteligencia narrativa' más cercana a la sabiduría práctica y al juicio moral que a la razón científica y teórica. Con base en esto, Ricoeur habla de una 'inteligencia phronética' que está en oposición a la 'inteligencia teórica' y tiene su sustento en la 'imaginación creadora'.

Entonces, mediante los relatos podemos acceder a nuestra propia vida, también apostar una comprensión de los entornos culturales, sociales o políticos. Pues, "toda historia bien narrada enseña algo; más bien, (...) la historia revela aspectos universales de la condición humana" (Ricoeur, 2006, p. 12). Así mismo, además de la comprensión de sí los relatos configuran la subjetividad. De este modo, con la configuración de la trama se produce al sujeto no solo en el acto de escritura u oralidad, sino 
en el de lectura; en el acto de leer está, para Ricoeur, la potencia del relato para transfigurar la experiencia del lector. A pesar de este realce de las historias contadas, es importante señalar la existencia de una vida prenarrativa en la cual somos un ser 'enmarañado en historias'. Es a partir del dinamismo de la composición narrativa que se configura la subjetividad en tanto identidad narrativa.

De esta manera, así como los textos se constituyen en relaciones intertextuales, nosotros lo hacemos en relaciones intersubjetivas mediadas por y en contraposición con la cultura y la tradición. En esta dinámica, la circulación de los relatos es un momento cumbre en la transfiguración de la subjetividad. Ahora, hay que señalar que el hecho de que las narraciones sean resultado y tengan su fundamento en lo relacional implica que sean comprendidas como parte de un entramado de relaciones de poder. Por ello, las narraciones son una herramienta para la formación de la subjetividad política. De igual modo, la ficción como parte de la razón narrativa es un instrumento para configurar nuevas subjetividades políticas.

Para desarrollar esto el artículo se divide en cinco partes: en la primera, se revisa con Ricoeur principalmente la relación entre vida y narración para concluir que la vida no puede ser vivida sin ser narrada y la historia produce experiencia y vivencias. Así, por un lado, el relato acompaña a la vida y de hecho el texto tiene la potestad de transfigurar la experiencia del lector $y$, por otro lado, la vida contiene las estructuras prenarrativas que dan sustento al relato. En el segundo apartado, se retoma la idea de que el texto puede transfigurar la experiencia del lector en el momento en que este último retoma la trama de aquel para señalar cómo la narración puede dar origen y transfigurar a la subjetividad. Entonces, la subjetividad es entendida como identidad narrativa. En la tercera parte, a partir de comprender la razón narrativa como una forma de inteligibilidad del mundo y de nosotros mismos se explora la posibilidad que da la narración para comprenderse a sí mismo y para transfigurarse por medio de la ficción del relato. En el cuarto momento, se retoma el paralelo entre el texto y la configuración del ser humano enmarcado en la dinámica entre sedimentación e innovación para abordar el carácter político de la narración. Esto es, la desviación que puede producir el texto en el lector y que da puerta abierta a la transfiguración de la subjetividad frente a las tramas impuestas por la cultura. Finalmente, se concluye que la circulación de los relatos, si existen las condiciones discursivas, permiten la formación de identidades vínculos tanto individuales como colectivos.

\section{LA CONDICIÓN PRENARRATIVA DE LA VIDA: UNA VIDA NARRADA}

Para Roland Barthes (1970) existe una presencia universal del relato en el mundo cultural humano. Así, las narraciones configuran todas las esferas de la acción, de la reflexión y con ellas a nuestra subjetividad. En todo caso, a pesar de la transversalidad del relato en nuestro mundo, Ricoeur señala que es importante revisar la asimilación automática entre historia y vida: "entre vivir y relatar se abre un espacio, por ínfimo que sea. La vida es vivida, la historia es relatada". (Ricoeur, 2002, p. 2). El autor francés enmarca su crítica a esta idea en el conocimiento elaborado sobre el relato y la actividad narrativa. "Un saber que parece alejar el relato de la vida en tanto que vivida y que confina el relato al campo de la ficción" (Ricoeur, 2006, p. 9). Frente a esto, el autor de Tiempo y narración, revisa la asimilación mencionada de tal manera que "la ficción contribuya a hacer de la vida, en el sentido biológico del término, una vida humana" (Ricoeur, 2006, p. 9).

En el mismo sentido, Delory-Momberguer (2015) en cuanto a la relación de la vida y el relato plantea las siguientes preguntas: "¿pueden los individuos humanos vivir la vida 
fuera del relato? ¿Puede la vida ser vivida sin ser contada? ¿Existe una vida humana que no esté en relación con ella misma?" (p. 2). Por su parte, Ricoeur revisa la respuesta que afirma que 'las historias son narradas y no vividas; la vida es vivida y no narrada'. Para su análisis y el replanteamiento de la relación entre estos dos polos retoma el concepto aristotélico de 'construcción de la trama'. Así, la trama o intriga es definida como una síntesis de elementos y acontecimientos heterogéneos que da lugar a una historia coherente. En consecuencia, el acto de configuración de la trama otorga un estatuto de inteligibilidad a la historia y la hace comprensible. De igual forma, además de este aspecto de orden epistemológico, la configuración de la intriga se inscribe en la tradición y las reglas destinadas para su organización. En este aspecto se da una dinámica entre innovación y sedimentación: sedimentación de aquello que pasa a ser parte de la tradición dentro de la actividad narrativa e innovación de aquello que logra desviarse de lo normativo.

Tomando como base los anteriores elementos Ricoeur se enfrenta a la paradoja abordada: "las historias se narran, la vida se vive. De este modo, un abismo aparece abrirse entre la ficción y la vida" (Ricoeur, 2006, p. 15). Para atravesar este precipicio el filósofo francés revisa los dos polos de la paradoja. Primero, al situarse en principio del lado del relato o de la ficción, muestra cómo esta acompaña a la vida y mantiene la tesis de que el proceso de configuración no se termina con el texto, sino con el lector. En este camino, afirma que es posible que el relato produzca una reconfiguración de la vida. Así, el sentido de un relato emerge en el encuentro entre el mundo del texto y el mundo del lector. En el acto de leer, nos dice Ricoeur (2006), "descansa la capacidad del relato de transfigurar la experiencia del lector" (p. 15). De ahí que, los relatos (auto) biográficos al ser leídos extienden la experiencia del lector y pueden crearle un mundo nuevo. De esta forma, en general, los textos operan como una mediación entre el hombre y el mundo, comunican al hombre con el hombre y posibilitan la comprensión de sí de cada ser humano.

Ricoeur denomina hermenéutica a la bisagra entre la conformación interna de la obra y la refiguración externa de la vida. Esta, la hermenéutica, busca ir más allá de la mera descripción referencial, busca encontrar formas de comunicación no utilitarias y descubrir una reflexividad no narcisista generada en la obra literaria. Así, puede decirse, que dicha forma de comunicabilidad se afirma en la dinámica de transfiguración que producen los textos en el lector. Esta se hace efectiva gracias a la trama que es retomada por el lector y se convierte en el elemento común entre este y el texto. El lector al encontrarse con el relato actualiza una y otra vez la acción configuradora que le dio origen a la trama. Entonces, se produce el juego entre innovación y sedimentación que pueda dar la posibilidad de 'desviación'. De esta manera, con el acto de lectura la obra concluye y deja ver un horizonte de posibilidades interpretativas indeterminadas; esto según cada nuevo contexto en que se dé. En suma, "el relato y la vida pueden ser reconciliados, ya que la propia lectura es ella misma una manera de vivir en el universo ficticio de la obra (...) las historias se narran, y también se viven imaginariamente" (Ricoeur, 2006, p. 16).

Ahora bien, luego de demostrar que el texto se vive, Ricoeur dirige la atención al otro polo de la paradoja para postular que la vida se narra. En este punto, el filósofo francés quiere subrayar el carácter pre-narrativo de una vida. Nos dice, "una vida no es más que un fenómeno biológico en tanto la vida no sea interpretada. $Y$ en la interpretación la ficción juega un papel mediador considerable" (Ricoeur, 2006, P. 17). Cabe señalar, para contrastar, que para Nietzsche la vida es ya un fenómeno interpretativo, es decir, que desde lo orgánico en sentido amplio es posible hablar de interpretación. 
Para dirigir la mirada al polo de la vida Ricoeur hace referencia a los elementos que constituyen la trama de una vida: la mezcla entre acción y sufrimiento. En este sentido, a partir de Aristóteles, quien define el relato como imitación de la acción (mimesis praxeos), encuentra tres anclajes que encuentra el relato en la vida para apoyarse en su creación narrativa. El primer punto de apoyo, que toma el relato de la experiencia para su inteligibilidad narrativa, es la estructura semántica, del actuar y sufrir humanos que nos permite comprenderla. De este modo, nuestra cercanía con el entramado conceptual de la acción es similar con el de las tramas de los relatos: "es la misma inteligencia phronética que guía tanto la comprensión de la acción (y de la pasión) como la del relato" (Ricoeur, 2006, p. 17). El segundo anclaje por el que la acción puede ser narrada es porque está ya 'mediatizada simbólicamente'. Estos símbolos implícitos o inmanentes conforman un 'contexto de descripción' que hacen inteligibles las acciones particulares. En este escenario pueden interpretarse y comprenderse los gestos que hacen de la acción un 'cuasi-texto' legible. Finalmente, el tercer punto de apoyo del relato en la vida es la 'cualidad pre-narrativa de la experiencia humana'. Es a partir de ella, resalta Ricoeur, que puede hablarse de la vida como una actividad y pasión que busca el relato. Esta familiaridad entre la vida y el relato no está dada solo por la red conceptual de la acción, con sus mediaciones simbólicas, sino también por la existencia de estructuras temporales que invocan a la narración.

Frente a lo anterior, Ricoeur señala una posible objeción al análisis realizado: el de acusarlo de circulo vicioso. Este es, el hecho de que si la experiencia está mediatizada por sistemas simbólicos lo está también por los relatos que escuchamos. Por ello, se pregunta “¿Cómo hablar entonces de una cualidad narrativa de la experiencia y de una vida humana como una historia en estado naciente, puesto que no tenemos acceso al drama temporal de la existencia fuera de las historias contadas más que por nosotros mismos?" (Ricoeur, 2006, p. 18). Para refutar la objeción el autor dirige la mirada a la estructura prenarrativa de la experiencia. En ella señala cómo la vida humana está compuesta ya por 'historias no contadas' o 'historias en potencia'. Es de la experiencia que surge el relato; más aún, es la transformación de estas historias no dichas en historias efectivas el lugar del nacimiento de la subjetividad como 'identidad narrativa'. Es necesario señalar que esta narración de nosotros mismos está mediada por los relatos de la cultura a la que pertenecemos. Como consecuencia, a pesar de que somos narradores de nuestra propia historia no siempre somos actores de ella. Es en este sentido, nos dice Ricoeur, que la vida se vive y la historia se narra; sin embargo, es posible que interpretemos de distintas formas las tramas de la cultura y escapemos a la petrificación de la identidad absoluta.

Esta reafirmación de que no es posible una vida sin historias se encuentra también, como lo muestra Delory-Momberger, en Wilhelm Schapp. "Para él, los sentimientos, las voliciones, las operaciones del espíritu, no solo no se dejan aprehender salvo en las historias, sino que no tienen otra realidad y otra existencia que las que tienen en las historias" (DeloryMomberger, 2015, p. 1). Incluso las ciencias físicas y naturales crean sus realidades a partir de historias. En este sentido, 'la vida' debe ser comprendida, incluso para el biólogo, desde la 'génesis del hombre' como 'un ser enredado en historias'. Es así como, lo 'biológico' y lo 'biográfico' se entrelazan. De este modo, en la pregunta '¿hay una vida sin relato?' el 'hay' puede ser comprendido en un nivel ontológico y en un nivel epistemológico. En este último aspecto, la narración se establece como una forma de inteligibilidad del mundo y la vida se comprende como 'biográfica', es decir, como el 'trayecto de vida' de un individuo. Por tanto, en relación con 
las preguntas de Delory-Momberguer, señaladas al inicio de este apartado, es necesario dirigir la mirada a la experiencia humana y al relato que se hace de ella como medio de compresión histórico y cultural.

\section{LA TRAMA Y LA FORMACIÓN NARRATIVA DE LA SUBJETIVIDAD: LA IDENTIDAD NARRATIVA.}

Lo narrativo no es, entonces, solamente el sistema simbólico en el cual los hombres disponen expresar el sentimiento de su existencia: lo narrativo es el lugar donde la existencia humana toma forma, donde se elabora y se experimenta bajo la forma de una historia

(Delory-Momberger, 2015, p. 5)

En el apartado anterior señalamos con Ricoeur que el nacimiento del sujeto está ligado al acto narrativo. Es decir que, cuando el sujeto se narra a sí mismo o relata su mundo surge al mismo tiempo que su relato. De esta manera, para el filósofo francés la subjetividad es comprendida como identidad narrativa. Entonces, el individuo puede ser entendido como un ser 'enmarañado en historias' no contadas, pero que en el momento en que realiza una selección de los acontecimientos para iniciar una historia está dándose forma a sí mismo. De este modo, "la historia da cuenta del hombre" (Ricoeur, 2006, p. 19). Por ello, como se insinuó antes, la narración tiene un lugar secundario que es antecedido por la estructura narrativa de la experiencia. Esta consecuencia que saca Ricoeur de su análisis existencial del hombre como un ser envuelto en historias implica que la comprensión de las historias tiene las bases de sus hilos en las historias no narradas. Por tanto, para entender mejor la relación entre el surgimiento del relato y del sujeto intentaremos mostrar cómo existe una relación entre la configuración de la trama y del sujeto.
El vínculo entre la existencia humana y la narración está atravesado por una "presencia universal" del relato. De ahí que sea imposible pensar la vida humana sin relato, dado que el hombre "relata para organizar y recordar su vida, su devenir en un contexto específico" (García, 2015, p. 156). Así, construimos y vivimos la vida narrativamente. "El relato está presente en todos los tiempos, en todos los lugares, en todas las sociedades; el relato comienza con la misma historia de la humanidad (...) el relato está allí, como la vida" (Barthes, 1970, p. 9). Entonces, nuestra relación con nosotros mismos, con los otros y con el mundo está mediatizada narrativamente. En este sentido, si la comprensión de lo que somos se da a través de una historia: "incluso el surgimiento corporal del hombre es solamente el surgimiento de sus historias; su rostro, su cara, cuenta a su manera, historias, y su cuerpo es solo cuerpo para nosotros cuando cuenta historias" (Schapp; citado por Delory-Momberger, 2015, p. 4).

Para matizar este nacimiento del ser humano a partir de sus relatos es importante dirigir la mirada a la configuración de la trama. Pues, un relato se caracteriza por estar configurado espacio temporalmente por una trama con sentido. Así, la 'puesta en intriga' o "la trama es la operación configuradora por la que hechos particulares y sucesos adquieren la forma de historia o de narración; por lo que cualquier acontecimiento, para que sea tal, precisa ser puesto en intriga, integrado en un relato" (Bolívar, Domingo y Fernández, 2001, p. 91). Junto con este proceso de configuración de la trama se constituye la 'identidad narrativa', pues los sujetos resultan de sus experiencias narradas. Por ello, los autores citados la definen como "la composición de intenciones, causas y azares que, al igual que en el relato, han ido configurando la vida" (Bolívar, Domingo y Fernández, 2001, p. 91).

En este sentido, para Ricoeur, es posible aplicar la comprensión de la 'concordancia discordante 
del relato y la discordancia concordante del tiempo' a la vida humana. Esta es construida por medio de la inteligencia narrativa y constituye nuestra identidad narrativa. Ricoeur resalta este último término justamente para señalar que la "subjetividad no es ni una serie incoherente de acontecimientos ni una sustancia inmutable inaccesible al devenir. Esta es el tipo de identidad que solamente la composición narrativa puede crear gracias a su dinamismo" (Ricoeur, 2006, p. 21). Ahora bien, para el filósofo francés entender la subjetividad en términos de identidad narrativa implica, entre otras cosas, que es posible aplicar a nuestra comprensión la dinámica entre sedimentación e innovación que se reconoce a la obra literaria. También, que es factible reinterpretar nuestra identidad bajo el foco de los relatos de la cultura a la que pertenecemos. Por tanto, al aplicar las tramas de nuestra cultura a la propia comprensión y experimentar por medio de las variaciones imaginativas sobre nuestro yo podemos alcanzar una comprensión sobre nosotros mismos. Estas variaciones sustentadas en los diferentes personajes de las historias permiten que la identidad narrativa se sitúe entre el cambio puro y la identidad absoluta.

De esta forma, afirma Ricoeur que:

Lo que llamamos sujeto no se da nunca al principio. O si se da, corre el riesgo de reducirse al yo narcisista, egoísta y avaro, precisamente del cual la literatura puede liberarnos. Entonces, lo que perdemos del lado del narcisismo, lo recuperamos del lado de la identidad narrativa. En lugar de un yo (moi) enamorado de sí mismo, nace un sí (soi) instruido por los símbolos culturales, entre los cuales se encuentran en primer lugar los relatos recibidos de la tradición literaria. Son estos relatos los que nos dotan, no de una unidad sustancial, sino de una unidad narrativa. (Ricoeur, 2006, p. 22)
Por tanto, la configuración del relato a partir de la vida y de la vida desde el relato está íntimamente vinculada con el carácter temporal de la existencia humana. Pues, "el hombre experimenta su existencia en el sentimiento de una unidad y de una identidad mantenida a través del tiempo" (Delory-Momberger, 2015 , p. 3). En esta existencia temporal el relato encuentra su anclaje: "el tiempo se hace tiempo humano en la medida en que se articula de un modo narrativo, y la narración alcanza su plena significación cuando se convierte en una condición de la existencia temporal" (Ricoeur, 2004, p. 113). Esta relación entre temporalidad y narración es señalada por Ricoeur al mostrar la capacidad de la ficción para re-figurar la experiencia temporal. Así, nos habla del 'valor mimético del discurso poético y del poder de redescripción de la ficción narrativa'. Para entender esto es necesario tener en cuenta el círculo mimético estudiado por Ricoeur: "la trama, dice Aristóteles, es la mimesis de una acción" (Ricoeur, 2004, p. 33). La trama, que tiene lugar en la mimesis II, cumple la función de mediación entre la "prefiguración del campo práctico y su refiguración por la recepción de la obra" (Ricoeur, 2004, p. 33). Ahora bien, justamente Ricoeur ve en las tramas que creamos una herramienta que sirve para reconfigurar nuestra experiencia temporal: "todos los sistemas de símbolos contribuyen a configurar la realidad. Más precisamente, las tramas que inventamos nos ayudan a dar forma a nuestra experiencia temporal confusa, informe $y$, en el límite, muda" (Ricoeur, 2002, p. 20).

De este modo, la ficción da forma a nuestra experiencia muda y desarrolla la función referencial de la trama como imitadora de la acción. En este sentido, la ficción da a las formas 
narrativas literarias esquemas de inteligibilidad que las configuran:

El mundo de la ficción es un laboratorio de formas en el cual ensayamos configuraciones posibles de la acción para poner a prueba su coherencia y plausibilidad (...) en esta fase, la referencia se mantiene en suspenso: la acción imitada es una acción solo imitada, es decir, fingida, fraguada. Ficción es fingere y fingere es hacer. El mundo de la ficción, en esta fase de suspenso, no es más que el mundo del texto, una proyección del texto como mundo. (Ricoeur, 2002, p. 21)

La ficción al reconfigurar la acción desvía el mundo normatizado. Con ello vemos que el texto enfrenta el mundo instaurado para rehacerlo: "la relación más paradójica del arte con la realidad sería incomprensible si el arte no descompusiera y no re-compusiera nuestra relación con lo real" (Ricoeur, 2002, p. 21). Es por ello, como medio de transfiguración del mundo y de la subjetividad, que el lenguaje es 'peligroso':

la ficción tiene ese poder de rehacer la realidad y, más precisamente, en el marco de la ficción narrativa, la realidad práctica, ya que el texto aspira intencionalmente a un horizonte de realidad nueva que hemos llamado mundo. Este mundo del texto interviene en el mundo de la acción para darle nuevas formas 0 , si se quiere, para transfigurarlo. (Ricoeur, 2002, p. 26)

Esta posibilidad que da el texto o el relato para transformar la realidad puede tener un tinte político cuando busca romper las estructuras de poder o las jerarquías en las que está inscrito el individuo. Entonces, la ficción opera como un artificio que mediante el relato individual o colectivo reconstruye la realidad en el momento en que se cuenta la historia (García, 2015, p. 196).
En suma, los relatos nos configuran como seres humanos dados el carácter prenarrativo de la existencia y nuestro ser comprendido como 'enmarañado en historias' no contadas: vivimos la vida narrativamente. Así, la comprensión de la subjetividad pasa por la posibilidad que tiene de organizar su experiencia junto con la configuración de las tramas. En este sentido, se postula que nuestra relación con el mundo, con nosotros mismos y con los otros está mediada narrativamente. Esto implica que interpretamos y comprendemos el mundo desde y con la narración, más aún, como se verá más adelante, a partir de la razón narrativa. En este camino, en la relación entre la narración y la temporalidad en la configuración de la trama aparece la identidad narrativa. Esta, aunque da orden a la discordancia temporal, se mantiene siempre en la dinámica entre sedimentación e innovación y con ella nosotros resistimos a la identidad absoluta y a la falacia del cambio puro.

\section{LA CONSCIENCIA NARRATIVA: CONOCERSE ES FABULARSE/INVENTARSE}

Hemos señalado que el lenguaje juega un papel fundamental en la construcción narrativa y por tanto metafórica de la realidad. También que en esta construcción de la experiencia y a partir de la experiencia se forma al sujeto. Así, existe un vínculo fuerte entre la construcción de la trama y la formación subjetiva. Esta conexión se debe a que no hay una relación trasparente de los seres humanos con lo que viven a través del tiempo. Es justamente el lenguaje y sus formas simbólicas los que median dicha relación. De este modo, los seres humanos por medio de palabras e imágenes "representan" el 'desdoblamiento' temporal y espacial de sus vidas. En esta configuración de sí mismo y de la realidad a partir de la narración (trama) se desarrolla lo que Ricoeur denomina inteligencia narrativa: una forma de pensamiento que el autor francés opone a la inteligencia teórica. A partir de esto, en este apartado dirijo la mirada 
a lo que significa dicha manera de pensar en la formación subjetiva para postular que mediante el relato no solo es posible que los sujetos se produzcan y se conozcan, sino que también se transfiguren.

Este lugar central del lenguaje como vínculo entre las vivencias y los seres humanos está íntimamente relacionado con la comprensión del ser humano como un ser que interpreta. De este modo, la narración debe ser entendida como una construcción interpretativa y ficcional. Por tanto, el lenguaje no es visto bajo la lupa metafísica como una herramienta para conocer los objetos tal cual son, sino que el acto de dar nombre es configurador de la realidad. En consecuencia, las investigaciones narrativas "no pretenden develar lo que está oculto en los escritos o en las experiencias, sino conocer, trabajar y actuar con los significados producidos, poniéndolos en relación con los contextos en el que se produjeron y producen" (Ministerio, 2005, p. 28).

Esta no concordancia entre el nombre y el objeto vincula la crítica del lenguaje a la crítica de la verdad. En este sentido, es posible ligar la reflexión que hace Nietzsche de la metafísica y del predominio de la razón con el realce que hace Ricoeur de la inteligencia práctica frente a la inteligencia teórica. Así, para Nietzsche lo que da sustento a la configuración de conceptos, de las palabras y del mismo lenguaje no es la lógica, sino la voluntad de ficción. Para Ricoeur, por su parte, lo nuevo surge en el lenguaje mediante la narración (y la metáfora) relacionado con la imaginación creadora; "dicha innovación semántica consiste en la invención de una trama, que también es una obra de síntesis"h (Ricoeur, 2004, p. 31). En este contexto, olvidamos que los nombres son convenciones que utilizamos a la manera de pacto colectivo para organizar el mundo. De hecho, Nietzsche define la verdad como una mentira colectiva y señala que mediante el ocultamiento de las metáforas usadas para designar el mundo se olvida su poder creador (Nietzsche, 2006, p. 25).

Así, los seres humanos escriben espacialmente su representación temporal de sus vivencias; sin embargo, usan imágenes para describir el curso de su vida que le son "tan familiares que pierden su dimensión simbólica o analógica y hacen olvidar que es solamente por metáfora, por las vías de la escritura, que tales representaciones pueden estar prestas a su existencia" (DeloryMomberger, 2015, p. 3).

Ahora bien, la anterior cita de Nietzsche sobre la verdad nos hace comprender que esta es plural y que las verdades han sido construidas por los múltiples pueblos a lo largo de la historia. Es así como Delory-Momberger señala la posibilidad de seguir el curso de nuestra historia y liga el curriculum vitae al curriculum stelarum. Con esto puede señalarse el papel primordial del relato en la configuración de la experiencia humana. Como ejemplo la autora recuerda la función fabuladora con la que Bergson señala la posibilidad que tienen los individuos y las sociedades de inventar personajes para contar sus historias. De hecho, muestra que mediante la representación narrativa los seres humanos se crean a sí mismos y le da un estatuto ontológico a la narración como configuradora de la acción.

La puesta en duda de la verdad universal y eterna busca resquebrajar la equiparación, del modo metafísico de ver el mundo, entre realidad y verdad. Los antecedentes de esta forma de pensamiento la encontramos en Sócrates, quien dio la primacía al concepto, a la teoría y a la consciencia sobre los instintos. De este modo, lo dicho por Sócrates: "todo tiene que ser consciente para ser bueno" fue llevado al mundo del arte: "todo tiene que ser inteligible para ser bello" (Nietzsche, 2000, p. 115). Como consecuencia la razón fue erigida como la forma por excelencia para encontrar la verdad. Ahora bien, con la ruptura de la verdad entendida como la correspondencia, entre la idea producida por el 
sujeto racional y el objeto, deja de tener su lugar preponderante el mundo de la representación.

Con la crisis de la razón moderna, en su versión lógico-matemática como regidora del mundo, se abre paso la comprensión del mundo desde lo corporal y lo simbólico. Esta nueva forma de pensamiento que se aleja de la forma metafísica de ver el lenguaje puede denominarse inteligencia o razón narrativa (Delory-Momberger, 2015, p. 6). La forma narrativa de pensar no es únicamente otra forma para expresarse, sino que, en tanto acción, nos conforma ontológicamente. Para DeloryMomberger existe una capacidad antropológica según la cual los seres humanos percibimos y ordenamos nuestra experiencia justamente en clave de una razón narrativa. La autora resalta que esta debe ser comprendida como una actitud primordial de las vivencias humanas: "aun antes de dejar de nuestra vida una huella escrita cualquiera, antes de todo discurso, oral o escrito, realizado sobre nosotros mismos, configuramos mentalmente nuestra vida en la sintaxis del relato" (Delory-Momberger, 2015, p. 6). De esta manera, construimos narrativamente nuestras experiencias y damos sentido a nuestras vidas.

Dicha construcción narrativa de la realidad está inscrita en el vínculo entre narración e interpretación. Pues, justamente la interpretación hace parte de la teoría narrativa al comprender al hombre como un ser que vive interpretativamente. En este sentido, Jerome Bruner(1997)contrapone los relatos como formas de acercarse a la realidad frente al conocimiento científico. Para el autor estadounidense, en este contexto, hay un paralelo entre el texto narrativo y el 'modo narrativo de pensamiento': "cada cual da forma al otro, al igual que el pensamiento se hace inextricable a partir del lenguaje que lo expresa y a la larga le da forma" (p. 152). De igual manera, nuestra experiencia toma el carácter de los relatos que empleamos para referirnos a ella; es así que la comprensión de la narración es hermenéutica.

Por tanto, cada acontecimiento tiene una posibilidad variada de interpretaciones. De este modo, el pensamiento racional o empírico queda sin sustento al abogar por una interpretación absoluta de la historia. Para Bruner, por el contrario, el análisis hermenéutico busca leer los textos apelando a la relación del todo con las partes y de estas con el todo. A partir de allí, se busca explicar el significado del relato de acuerdo con los 'detalles particulares'. Esto es lo que implica el 'circulo hermenéutico': "intentar justificar la "adecuación» de una lectura de un texto, no por referencia al mundo observable o a las leyes de la razón necesaria, sino por referencia a otras lecturas alternativas" (Bruner, 1997, p. 156). Dichas lecturas alternativas implican perspectivas determinadas subjetivamente. En consecuencia, frente al conocimiento objetivo de la cosa tal cual es pregonado por los positivistas, "las construcciones narrativas de la realidad nos llevan a buscar una "voz»" (Bruner, 1997, p. 158).

Esta posibilidad interpretativa de leer la realidad tiene que ver con el "estatuto de inteligibilidad que conviene conceder al acto de configuración" (Ricoeur, 2006, p. 12). En este marco de referencia, el autor francés recuerda cómo Aristóteles señalaba que las historias narradas siempre enseñan algo y que además que a partir de las historias podían develarse elementos universales de la humanidad. De hecho, Ricoeur muestra cómo los géneros que conocía Aristóteles "desarrollan una clase de inteligencia que podemos denominar inteligencia narrativa, que se encuentra más cerca de la sabiduría práctica y del juicio moral que de la ciencia $y$, en un sentido más general, del uso teórico de la razón". (Ricoeur, 2006, p. 12). De acuerdo con esto, Ricoeur habla de una inteligencia en el sentido que Aristóteles le daba a la phrónesis (prudentia). Dicha inteligencia pertenece a la 
inteligencia phronética en contraposición a la inteligencia teórica y surge de la imaginación creadora.

La teoría narrativa sustentada en la acción y en la razón narrativa se constituye en una forma de interpretarse, es decir, de comprenderse a sí mismo y a los demás. En concordancia, para Jorge Larrosa (2003) una teoría narrativa entendida de esta manera implica unas ideas filosóficas sobre la formación de la identidad del sujeto, la autoconciencia, la autocomprensión. Así mismo, dicha teoría estaría relacionada con las prácticas como lugares de producción, interpretación y mediación de historias (p. 607). Para Larrosa, en sentido similar como se señaló antes con Bruner, existe una analogía entre un texto narrativo y lo que somos:

el sentido de quien somos es análogo a la construcción y la interpretación de un texto narrativo $y$, como tal, obtiene su significado tanto de las relaciones de intertextualidad que mantiene con otros textos como de su funcionamiento pragmático en un contexto. (Larrosa, 2003, p. 608)

Esto refuerza la idea de que como sujetos nos constituimos en relaciones de intersubjetividad que además de implicar las relaciones de alteridad pasan por la tradición, la cultura y nuestros antecesores.

En resumen: quién somos como sujetos autoconscientes, capaces de dar sentido a nuestras vidas y a lo que nos pasa, no está más allá, entonces, de un juego de interpretaciones: lo que somos no es otra cosa que el modo como nos comprendemos; el modo como nos comprendemos es análogo al modo como construimos textos sobre nosotros mismos; y cómo son esos textos depende de su relación con otros textos y de los dispositivos sociales en los que se realiza la producción y la interpretación de los textos de la identidad. (Larrosa, 2003, p.610)

Lo anterior muestra que existe una clara relación entre la interpretación, la narración y la formación de la consciencia. En este camino, Delory-Momberger (2015) refiere cómo desde las neurociencias se toma la 'competencia narrativa' como un hecho biológico que permite postular la existencia de un módulo que interpreta y da sentido a nuestra vida al organizar las vivencias en el relato; también nos remite con Dennett a la 'estructura narrativa de la conciencia'. Así, la narración nos permite dirigir la mirada a nosotros mismos, a los otros y al mundo para conocernos; sin embargo, como se ha señalado, también se constituye en una herramienta de proyección: "la narración es una fuente de transformación infinita, mediante ella no solo es posible transfigurar la materia, sino la propia y ajena subjetividad" (Parra, 2019, p. 409).

Dicha transformación está dada también en cuanto que al contar su historia los sujetos pueden hacer una reinterpretación de los acontecimientos. Por tanto, configurar una narración requiere "seleccionar hechos o episodios de lo que se vivió y configurar con ello una cierta unidad de sentido, una intriga, que otorga significado a aquello que, de otra manera, aparecería disperso y sin relaciones mutuas" (Ministerio de Educación Ciencia y Tecnología, 2005, p. 28). Es por esta razón que puede decirse que los relatos son ficticios en cuanto implican una edición de la propia vida. Para García (2015): "esta edición no es más que la forma como desea presentarse ante la audiencia y ante él mismo: una versión de quien es y cómo ha llegado a ser" (p. 196). En dicha versión, dice Leonor Arfuch (2010), lo que importa no es el contenido mismo del relato, "sino, precisamente, las estrategias-ficcionalesde auto-representación lo que importa. No tanto 
la "verdad" de lo ocurrido, sino su construcción narrativa" (p. 60). Aquí surgen múltiples historias de sí mismo llenas de silencios, vacíos conscientes o no; poco importa si el narrador se ha inventado un suceso, pues este hace parte efectivamente de lo que fue o será.

En suma, se ha postulado, bajo la premisa de que el ser humano es un ser interpretante, que la narración es una construcción interpretativa y ficcional. A través de la narración comprendemos el mundo, a nosotros mismos y a los otros. Comprensión que está enmarcado dentro de la posibilidad que da la inteligencia narrativa como forma inteligible de la realidad. Ahora bien, esta aprehensión del mundo por medio de la razón narrativa implica que no solo podemos conocernos a través de ella, sino también transfigurarnos. Esto es gracias a que al construir las historias reinterpretamos el pasado, pero también podemos ficcionalizar el futuro e imaginarnos nuevas formas de ser. Así, la razón narrativa se presenta como una forma de ver el mundo alternativa a la razón instrumental y teórica.

\section{LA NARRACIÓN (FICCIÓN) EN LA FORMACIÓN DE LA SUBJETIVIDAD- POLÍTICA: CIRCULACIÓN DE RELATOS Y ALTERIDAD}

Existe un paralelo entre las relaciones intersubjetivas y las relaciones intertextuales. Dichas relaciones están inscritas en un juego entre la tradición y la innovación; por lo tanto, pueden darse en contraposición con la cultura y la tradición. Es así como, los sujetos tienen la posibilidad de reinterpretar las tramas culturales y "escapar" de la subyugación de la identidad absoluta. En este proceso lo narrativo media nuestras interacciones con el mundo, con los otros y con nosotros mismos. Por tanto, de la mano de la imaginación creadora y de la razón narrativa surgida de ella los sujetos tienen herramientas para formar, desviar y transfigurar su subjetividad: mediante la configuración de las tramas y la circulación de los relatos se sedimentan e innovan maneras otras de entender y vivir el mundo, formas otras de ser y estar de los sujetos, maneras otras de relacionarnos y encontrarnos con los otros.

Al retomar la relación entre la configuración de la trama y la configuración de la subjetividad puede mostrarse el carácter político, en algún sentido, de la narración. La trama es también, como muestra Ricoeur (2006), una síntesis de elementos muy heterogéneos. "La reunión de todos estos factores en una única historia hace de la trama una totalidad que podemos denominar a un tiempo concordante y discordante (por eso prefiero hablar de concordancia discordante o de discordancia concordante) (p.11). Esta caracterización de la trama tiene que ver con el carácter temporal de la narración, pues justamente el tiempo pasa y se nos escapa, pero también permanece. Por ello, Ricoeur habla de la identidad temporal de las historias como lo que dura a través de lo que pasa. En un sentido más amplio, en el de la identificación de los modelos narrativos, la constitución de eso que dura (la tradición) se desarrolla en la relación entre la innovación y la sedimentación. Esta dinámica es paralela a la constitución de la identidad narrativa del sujeto que se desenvuelve, en términos políticos, en la lucha por escapar de la determinación absoluta.

Así, el carácter político de la narración está dado, entre otras cosas, porque está inscrita en un determinado contexto. Por tanto, "la construcción narrativa está influida profundamente por las circunstancias culturales e históricas" (Bruner, 1997, p. 155). En este sentido, los relatos dan cuenta de las relaciones de poder que los atraviesan, pero permiten ver también la respuesta pasiva o activa de los sujetos a las determinaciones contextuales. Por tanto, a pesar de la influencia externa sobre los sujetos y los relatos, estos no son determinados de manera absoluta: "siempre hay un elemento 
de libertad implicado en la narración; alguna agencia que puede inmiscuirse en una supuesta cadena causal. La agencia presupone la elección" (Bruner, 1997, p. 156). Así, de manera permanente hay un espacio para la innovación, el momento en el que aparece la singularidad y que permite señalar que una obra o un sujeto es este y no otro. Esto claro está se da siempre en interacción con la tradición, pero llega un momento en el que "la desviación prevalece sobre las reglas" (Ricoeur, 2002, p. 14).

El espacio para la innovación puede ser construido por medio de los relatos. Estos, mediante la ficción, tienen "el poder de otorgar un acrecentamiento de ser a nuestra visión del mundo empobrecido por el uso cotidiano" (Ricoeur, 2004, p. 153). En este sentido, en la escritura y en el análisis de las narraciones, el contenido y la 'intención del autor' pasan a un segundo plano en relación con el hecho de que se produce una 'refiguración' de la experiencia. Lo importante es, dice Ricoeur (2004), "explicitar el movimiento por el que el texto despliega un mundo, en cierto modo, delante de sí mismo" (p. 153). Pues, "el hacer narrativo resignifica el mundo en su dimensión temporal, en la medida en que narrar, recitar, es rehacer la acción (...)" (p. 153).

De esta manera, se evidencia la influencia de la literatura, y por tanto de los relatos, en la vida cotidiana. Negarla, nos dice Ricoeur (2004), es darle cabida al prejuicio positivista que dice que prevalecen los datos y lo empíricamente describible y "encierra la literatura en un mundo en sí y se rompe la punta subversiva que lanza contra el orden social y moral. Se olvida que la ficción es precisamente lo que hace del lenguaje ese supremo peligro" (p. 151). Por tanto, los relatos, y su carácter ficcional, abren un horizonte de disputa entre lo que se considera real y lo posible; el mundo del como sí se abre paso. El fenómeno de desviación frente a lo tradicional da lugar a la singularidad no solo de las obras, sino de la misma subjetividad. Esto ocurre también gracias a la fusión de los horizontes del mundo del texto y el mundo del lector. Así, el mundo es configurado por los textos o relatos a los que tengo acceso y que han afectado lo que soy: "a las obras de ficción debemos en gran parte la ampliación de nuestro horizonte de existencia" (Ricoeur, 2004, p. 152).

Con base en lo anterior, es posible postular la idea que la circulación de relatos (auto) biográficos abre la posibilidad de transfigurarnos a partir de escuchar o leer la historia de los otros; en cierto sentido, también de encontrarnos con la alteridad y su singularidad. Este proceso por el cual se comparte una historia implica no únicamente "que alguien tome la palabra y se dirija a un interlocutor, también en que desee llevar al lenguaje y compartir con otro una nueva experiencia, que a su vez, tiene al mundo por horizonte" (Ricoeur, 2004, p. 149). Esto implica, como señalamos antes, que todo discurso tiene una referencia, que cuenta algo sobre el mundo y que por tanto está inscrito en un contexto. Así, por medio de los relatos el otro nos comunica su sentido del mundo tanto como el horizonte de su mundo: "el oyente o el lector lo reciben según su propia capacidad de acogida" (Ricoeur, 2004, p. 148).

La capacidad de acoger al otro implica la consciencia de que no somos sin los otros. En este sentido, "obrar es siempre obrar "con" otros: la interacción puede tomar la forma de la cooperación de la competición o de la lucha" (Ricoeur, 2004, p. 117). Es decir, no es necesario pensar en que en la circulación de los relatos el encuentro con el otro será armónico, pero puede esperarse que se tome una posición frente a lo que nos afecta del otro. Esta afectación implica recuperar el espectro político, pues:

la política surge de la relación, del entre, en donde la acción del agente revela su identidad a través de una narrativa que sólo adquiere inteligibilidad y coherencia 
en el conjunto de tramas y relatos en las que nos, es decir, en los espectadores de nuestras acciones. (Gómez, 2013, p. 90)

Este reconocimiento de que la política opera con un fundamento relacional lleva a definir la subjetividad política como "una dimensión de ese ser humano que somos y que vamos siendo con otros" (Ruiz y Prada, 2012, p. 35). Por ello, los autores señalan la importancia de reconocer la responsabilidad, en tanto seres creadores, con el mundo por venir. Esto acorde con un movimiento de subjetivación que "implica reconocernos capaces de configurar mundos posibles y de transformar el que habitamos, esto es, proyectar nuestras acciones en aras de construir un mundo más humano en el que podamos vivir y que podamos legar a las generaciones futuras" (p. 35). "Subjetivarse implica, entonces, transformarse en actor de la vida misma personal, es lo contrario a unos valores trascendentales o enajenados" (Gómez, 2013, p. 24). Así, en este contexto, Ruiz y Prada (2012) se preguntan justamente ¿Cómo agenciar procesos de construcción crítica y transformadora de la subjetividad? (p. 36).

Precisamente, las narrativas (auto) biográficas son herramientas que generan agencia política no solo porque mediante la narración se forman elementos constituyentes de la subjetividad como la temporalidad, la memoria, la identidad, la proyección y la consciencia (Ruiz y Prada, 2012), sino porque mediante los relatos se configuran posiciones de sujeto en los entramados de las relaciones de poder. Es decir que, en los contextos formativos, las narraciones ayudan "a los alumnos a que adopten una posición personal en su vida, a que discutan los sentidos de la realidad con la que se encuentran y a que construyan otra mejor, más humana" (Gil, 1997, p. 133). En este proceso pueden construirse vínculos con los otros o por lo menos "ponerse en el lugar del otro, representar sus sentimientos y sus intenciones y comprender sus acciones en el marco de una historia" (Delory-Momberguer, 2015, p. 6).

\section{CONCLUSIÓN}

Los relatos (auto) biográficos, entendidos como narraciones ficcionales, son herramientas de formación, configuración y transfiguración de la subjetividad. En tanto, son fuente de experiencia, la construcción individual y colectiva de relatos produce identidades narrativas ancladas en determinados contextos como los formativos. De este modo, mediante la circulación de narrativas escritas $u$ orales es factible que los sujetos se encuentren en una trama con sentido que no es necesariamente armónica. Así, al adentrarse en los horizontes vitales de los otros por medio de sus historias el propio mundo se ensancha y da lugar, si existen las condiciones para ello, a la conformación de subjetividades políticas que, por medio de la imaginación creadora y la razón narrativa, tejan una experiencia colectiva en diálogo con la tradición.

\section{REFERENCIAS BIBLIOGRÁFICAS}

Arfuch, L. (2010). El espacio biográfico. Dilemas de la subjetividad contemporánea. Argentina: Fondo de Cultura Económica.

Barthes, R. (1970). Introducción al análisis estructural de los relatos. En: Análisis estructural del relato. Buenos Aires: Editorial Tiempo Contemporáneo.

Benjamín, W. (1998). Para Una crítica de la violencia y otros ensayos. Iluminaciones IV. Madrid: Taurus

Bolívar, A. Domingo, J y Fernández, M. (2001). La investigación biográfico-narrativa en educación. Enfoque y metodología. Madrid: Editorial la Muralla.

Bruner, J. (1997). La educación puerta de la cultura. Madrid: editorial Visor. 
Delory-Momberger. (2015). La condición biográfica. Ensayos sobre el relato de sí en la modernidad avanzada. Medellín: Editorial Universidad de Antioquia.

García, V. (2015). La creación del sí mismo. Verdad y ficción en los relatos de vida. En: Revista Mexicana de investigación, Vol. 29. Núm. 64. (Pp. 195-218). Recuperado de: http://www.redalyc.org/ pdf/140/14032722010.pdf

Gil, Fernando. (1997). Educación y narrativa: la práctica de la autobiografía en la educación. En: Teoría Educativa. 9. pp. 115-136. Ediciones Universidad de Salamanca.

Gómez, Esteban. (2013). Testigos de sí mismos. Narrativas políticas de jóvenes bogotanos. Bogotá: Universidad Distrital.

Larrosa, Jorge. (2003). La experiencia de la lectura. Estudios sobre literatura y formación. México: Fondo de cultura económica.

Ministerio de Educación Ciencia y tecnología y OEA (AICD). (2005). La documentación narrativa de experiencias pedagógicas. Una estrategia para la formación de docentes: Buenos Aires.

Murillo, Gabriel. (2016). La investigación biográfico narrativa en educación en Colombia siglo XXI. Medellín: Universidad de Antioquia. Tesis doctoral.

Nietzsche, F. (2006). Sobre verdad y mentira en sentido extramoral. Madrid: Tecnos.

Nietzsche, F. (2000). El nacimiento de la tragedia. Madrid: Alianza editorial.

Paredes. L. (2011). Cambiar el panorama de las escuelas. Indagación narrativa, artes visuales y tecnologías de la información y la comunicación en una escuela activa radical. En: Bautista, A y Honorio, M. (coordinadores). Antropología visual: medios de investigación en educación. (pp. 152-173). Madrid: Editorial Trotta.

Parra, E. (2020). Voluntad de ficción, subjetividades políticas y narrativas (auto) biográficas. Una experiencia de formación política con estudiantes de secundaria. Bogotá: Universidad de los Andes. Tesis doctoral. Recuperado en:

https://repositorio.uniandes.edu.co/bitstream/ handle/1992/48385/u833949. pdf?sequence $=1$

Parra, E. (2019). Representaciones y narraciones formativas de la alteridad. La subjetividad política como escenario de relación y de conflicto. Análisis, 51 (95), 389-416. Recuperado en:

https://revistas.usantotomas.edu.co/index.php/ analisis/article/view/4756/pdf

Ricoeur. P. (2006). La vida: un relato en busca de narrador. Agora (papeles de filosofía) 25/2, pp. 9-22. Recuperado en:

https://minerva.usc.es/xmlui/bitstream/ handle/10347/1316/Ricoeur. pdf?sequence $=1$

Ricoeur. P. (2004). Tiempo y narración 1. Configuración del tiempo en el relato histórico. México: Siglo xxi editores s. a.

Ricoeur, P. (2002), Del texto a la acción. Ensayos de hermenéutica II. México: Fondo de Cultura Económica.

Ruiz, A. y Prada, M. (2012). La formación de la subjetividad política. Propuestas y recursos para el aula. Buenos Aires: Paidós. 